\title{
Las ordenanzas municipales. Algunas propuestas para su estudio y un ejemplo
}

\author{
Pedro A. Porras Arboledas *
}

Cada día son más las Ordenanzas municipales que salen a la luz, publicadas tanto por historiadores de las Edades Media y Moderna. como por historiadores del Derecho, lo que es prueba del interés que tales textos jurídicos levantan como testimonios vivos del pasado. Realmente esto es así debido a la contingencia con que fueron creadas. fruto de necesidades reales de los concejos, lo que hace que tengan una frescura de la que carecen otios textos, jurídicamente más relevantes, como los fueros municipales heredados de la Alta y Plena Edad Media

De hecho, si las ordenanzas llegan a configurarse es a causa de la rigidez que habian alcanzado tales fueros, que se habian convertido en auténticas antiguallas a fines de la Edad Media. Esto se habia producido por dos razones: en primer lugar, por la asunción por parte del poder real de la capacidad legislativa, introduciendo normas más acordes con la realidad bajomedieval - procedentes del Derecho de la Recepción-, que acabaron derogando de facto buena parte del contenido de los viejos fueros, y, en segundo lugar, debido a que las materias que luego integrarían el elenco de competencias de los municipios y. por ende, las materias de ordenanzas, se habian quedado obsoletas, por contener disposiciones

Protesor Titular de Historia del Derecho. Universidad Complutense de Madrid.

Durante varios anos he impartido cursos de doctorado sobre estos temas y como fruto de los mismos quiero exponer ahora algunas de las conciusiones a que hemos llegado: se trata de una llamada de atención a los estudiosos de nuestra historia juridica de una fuente cuyo valor normativo no es en absoluto despreciable. en especial en lo que se refiere a los origenes del Derecho Administrativo y. más concretamente. al derecho sancionador y al procedimiento administrativo. perfectamente rastreables en estos modestos -aparentemente textos 
muy rigidas. en absoluto adaptadas a las realidades y a las necesidades concretas de cada municipio.

Efectivamente. al estudiar las ordenanzas - que empiezan a aparecer a lo largo del siglo xIV. generalizándose durante la centura siguiente- se aprecia una enorme variedad en cuanto al contenido, articulado, materias, procedimientos, etc., incorporados en las mismas. de modo que no es fácil sumergirse en este entramado tan variado de normas locales.

Dos conclusiones provisionales podemos extraer de lo dicho: por una parte. que la capacidad autonormativa de los concejos se habia manifestado. entre los siglos $x \mid$ y $x \| 11$, en la confección de textos forales. caidos progresivamente en desuso durante la Baja Edad Media, como producto de la recepción del Derecho Comun. que arrincona el viejo derecho e impone la supremacia legiferante del poder real. Es de ese modo cómo desde mediados del siglo xiv o, en la mayoria de los casos. desde los inicios del xv, a los municipios se les comprime su ámbito de competencias y. por tanto. su capacidad de legislar sobre las mismas. Este segundo momento vendra representado por las ordenanzas municipales y como tales se mantedrán hasta nuestros dias.

En definitiva, se trata de un claro ejemplo del avance del aparato administrativo central -sólo más tarde se podrá hablar plenamente de Estado- en detrimento del mundo local. Una segunda conclusion pasaría por resaltar, no obstante lo dicho. la importancia de iniciar el estudio del universo de las ordenanzas medievales y modernas a partir de los fueros. Genéticamente está clara la relación entre ambas clases de textos: los fueros tendían a ser auténticos compendios del ordenamiento juridico de una localidad: con lo que nos encontramos con que. además de recoger más o menos extensas relaciones de derecho privado. penal. procesal o mercantil, también contenian disposiciones sobre la organización adminis-

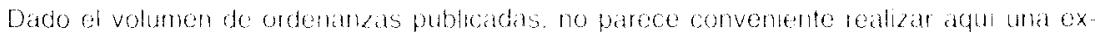
postorn detaliada de las mismas. si ben debe resenarse la labor desempenada en este sentido

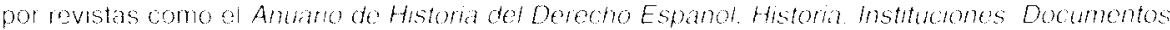

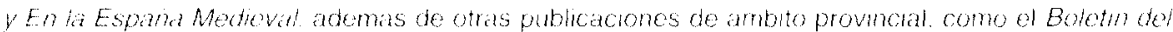
irstuto de Estudios Giemonses o Andes Tolodanos. lista a la que con seguridad pueden anadire utras muchas levishas de ese mismo anbio En cualquer caso. contamos con una expostcion general. debida a Lali mo. Miguel A y Ga M. ISabel. Las ordenamas locales on la Coroma de Castilla como fuente nistorica y tema de investigacion. Analos de la Unversiad de Alcante.

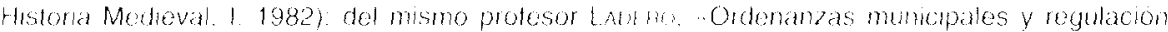
de la actividad economica en Andalucia y Canarlas (siglos xtu-xul) " Cologuo de Hotora Camala. 1977

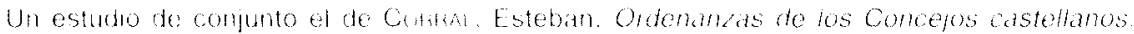
Formacion. contendo y mantestaciones (s. kil-x)!H). Burgos 1988 
trativa del municipio. policía rural, policia urbana, abastos, organización gremial, propios, etc.

Con la asunción por parte de la administración regia de la capacidad de legislar en aquellos temas. a los municıpios sólo les quedarán estas últimas materias como objeto de sus competencias. Asi pues; resulta del máximo interés estudiar, como paso previo, la regulación de estos últimos temas en los fueros. para comprobar esta relación material y, por supuesto. para determinar si esa misma correspondencia se observa también en los contenidos. En especial, la investigación deberia dirigirse hacia el estudio del Fuero de Cuenca y los de Sepúlveda y su entorno. sin olvidar las disposiciones que pueden rastrearse tanto en el Fuero Juzgo como en el Fuero Real: en especial en el primero de estos textos también se recogen numerosas disposiciones (las contenidas en los cinco últimos títulos del libro octavo) que luego serian materia de ordenanzas, en un proceso de despenalizacićn de distintas conductas luego castigadas como infracciones en las normas de policia rural.

A veces hallamos textos intermedios entre fueros y orderianzas que son del maximo interes, como es el caso de los usos y costumbres del Concejo sevillano en la época de Aifonso $x$ : estos cuadernos nos informan de la creación y puesta por escrito por parie del municipio de un conjunto de normas sobre cuestiones de régimen interior, al margen de su fuero, el cual

Un cuemplo de esta correspondencia nos io otrece Abin Ali. E. de la C. en sus Ordomalzas de Comm de ha vila de Segua y su toma de 1580 daen. 1980 . donde enchenta una relacion di-

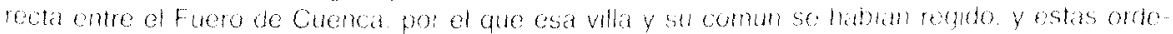
nanzas en relacion con la reserva a los vecmos de los aprovechamentos locales is 70). Iricluso.

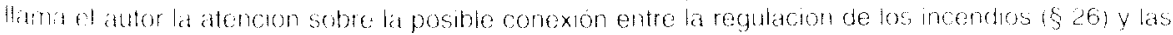
disposiciones correspondientes del Fuero Juzgo (8.2.8. antiqua)

En las Ordenanzas de Jaen se constata claramente el uso del Fuero Juzgo at menos. en dos

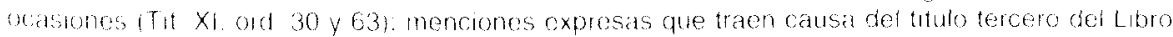
octavo del libe;

Gi.mi: Ant, J. D Cuadernos de ordenanzas y otros documentos sovilanos del ren.

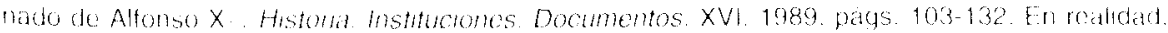
se tecogen varas ordenanzas de goberno del ano 1248 y el extracto de varios acuordos de ca. tuldo del perlodo $1272-1275$

Los tomas tratados nos mitoman de un modo meridano de las competencas atrabuidas at concejo ya desde la conquista femandina: en prmer lugar. nos indican la existencia de un complejo ciganigrama de otoios municipales de cabldo y auxilares asi como de las competencias cas plenas en materia de justicia hacienda y ejercito. Mucho mas completo es el control mumcipal sobre sus atribucionos adminstrativas relativas a la polica rural y urbana abastos obras publucas. order publico precos y sataros y sandad). Tambien aparecen reflejados to que he dado en liathar los medios de gestion dol concejo concesiones de uso conthuado de biones propios del municipio licencias para realizar actos concretos sometidos a control concejl y registros ubligatorios do diversos bienes y personas es decr to que hoy donommanos tecnicas der mterveriorom adm mistrativa. 
apenas preceptuaba nada, aparte de unos privilegios al concejo y a los caballeros y una remisión genérica al Liber - salvo las normas de policía rural contenidas en el libro VIII-. De la sedimentación de esos usos y costumbres y de su ampliación posterior proceden las ordenanzas del siglo $\mathrm{xV}$.

La vitalidad de las ordenanzas, por su adaptación a las realidades que pretendian regular, se manifiesta en la pervivencia de las mismas durante largo tiempo, siendo modificadas de acuerdo con los cambios de las circunstancias, aunque se da el caso frecuente de que habiéndose extraviado las mismas, al cabo de unos años, el concejo volvía a redactarlas sin tener demasiado en cuenta las anteriores, como he tenido la ocasión de comprobar en el caso de las ordenanzas de Jódar; sin embargo, cuando las ordenanzas se recopilaban su capacidad de resistencia al paso del tiempo era mucho mayor, si bien también estaba más próxima la posibilidad de que quedasen anquilosadas, tal y como les había ocurrido a los fueros. En cualquier caso, otro punto sobre el que se debe llamar la atención son las materias recogidas en los textos recopilados, ya que hay una gran diversidad en la elección de los temas ${ }^{b}$.

Desde mi punto de vista, habría que resaltar dos principios que presidian la redacción de las ordenanzas locales: por una parte, la observancia del bien común ${ }^{6}$ o la utilidad pública, concepto de elaboración clásica y patrística, que presuponía que el interés general debía estar por encima de los intereses particulares; de hecho, este concepto está intimamente ligado con otro que alcanzará una gran perdurabilidad: el de "policia», noción que merecería se le dedicase un estudio desde el punto de vista meramente histórico ". Este otro concepto, de origen romanista, representaria

En la actuaiidad, me encuentro redactando un amplio trabajo titulado El Concejo de Jaen (1476-1523). Organizacion. competencias y medios de gestion. donde desarrollo las ideas antes indicadas. La base del trabajo son varios miles de registros provenientes de los libros de actas de cabildo gienenses.

La publicacion reciente de las Ordenanzas de Ecija. recopiladas por la autora entre las anotadas en los libros de actas del cabildo. nos indica la riqueza que la totalidad de las ordenanzas de un municipio podian llegar a alcanzar. a despecho de lo cual los concejos efectuan una selección tematica en el momento de recopilarlas (Martin. Marina. Ordenanzas del Concejo de Ecija (1465 1600). Sevilla 1990).

Por ejemplo, en la recopilación jienense no se recoge nada del régimen gremial y muy poco de los temas de policia urbana. siendo las materias mejor tratadas la organización del municipio y la administración de los bienes de propios. Porras Arbolfuas, P.A. Ordenanzas de la Muy Noble. Famosa y Muy Leal ciudad de Jaén. guarda y defendimiento de los Reinos de Castilla. Granada. 1993.

Sanio Tomas de Aouino. La ley (version y notas de Constantino Fernández-Alvar) Barcelona 1936, pags. 141-144

Desde el purito de vista del Derecho Administrativo existen varios trabajos. que no llegan a introducirse en los origenes históricos del concepto. ospecialmente debidos al profesor NIETo. A. 
el instrumento para conseguir la realización del bien común; en términos generales, podria equipararse con el de potestad administrativa. La referencia más antigua que hemos hallado procede de un ordenamiento de Cortes de Juan II", aunque sin duda es anterior.

Por otro lado, el segundo principio sería el de la preservación del término y recursos de la localidad a favor de los vecinos de la misma; los forasteros quedaban fuera de sus beneficios, estando cualificadas las infracciones cometidas por los mismos con respecto a las de los moradores de la localidad. Ello era asi por entenderse que sólo los que contribuian a las cargas comunes podian beneficiarse de los recursos comunes; esto daria lugar a fines de la Edad Media, en el plano financiero, a buen número de pleitos por la doble imposición que alcanzaba aquellos propietarios de tierras en una localidad de donde no eran vecinos.

La prohibición de la entrada en términos ajenos a forasteros suele aparecer expresa o implicitamente en todas las ordenanzas de policía rural ", asi como la interdicción de exportar fuera de los términos propios los recursos de los mismos ".. Este principio estaba conectado con la tutela concejil de los aprovechamientos propios y la preservación del abasto local.

En otro orden de cosas, resulta de interés el proceso de aprobación de las ordenanzas: si en la Edad Media los municipios dictan sus normas

\footnotetext{
1. Algunas precisiones sobre el concepto de policia. Revista de Administracion Publica. LXXXI. 4976. págs. 35-75: "El sistema gubernativo y judichal de la Monarquia Absoluta". Estudios histo. hios sobre Admmstracion y Dorecho Administrativo Madrid 1986. pags. 67.142. y Derecho Acmmistratwo Sancionador. Madrid 1993)

En la prmera petición de las Cortes de Valladolid (1440) se exponia "... todo esto afyr que la cusa publica sea regida en toda buena policia e governada e sostenida en verdat e justici6. 1.. osto sea el bueno e loable regimiento aprovado por todos los sabios.. Versaba la cues "lir sor re temas de ordon público: respondió el monarca "... porque el servicio de Dios e mio e aur de la comat reai de mo regnos e el ben publico dellos se guarde sobre todas cosas. e disen todus escandalos e incomilientes... (Cortes de los artiguos reinos de leon y de Castila pubicados por la Real Academíi de la Historia. Madrid 1866.1ll. pags 369 y 373 ).

Sin embargo dicho concepto yo reogido en las ordenanzas parisinas de comenzos del siglo * se puede rastear clatamente en el iaplato inicial de Castillo de Bovadilla (Pollica para

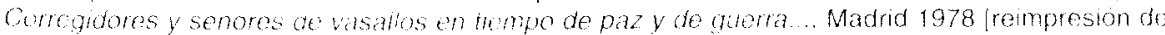
lat adion de Amberes do 1704|. hbro 1. capitulo 1. pags. 6, 7. 8 y 12, y libro II capitulo 1. pay 215) Jon de gran interes las apleatciones do Pablo Fuenteseca en cuanto a tos origenes del termimo pokcia y si recepcion en nuestra Peninsula ("De la Res Publica romana al Estado Moderno. Jumed Intemationdes ditistome de Drot. Bibao 1992. pags. 57-58. 84-85 y 87-881

Verare el articulo 29 de las ordenanzas de El Burrueco (Ponfas. P. A . El proceso de re) daccion de has Ordenanzas de Jaen. Dos ordenanzas de policia rural (siglos xiv y xul. Cuidemos de Estudos Medevales y Ciencias y Tecnicas Histonograficas. XVII. 1992. doc 4. Púg. 439

Vease el preambulo y aticulos 7 y 11 de las ordenanas do rapateros de Ubeda lácu mento 21
} 
de régimen interior sin recabar posteriormente la sanción real. desde finales del siglo xv los monarcas se inmiscuyen progresivamente en el refrendo de tales ordenanzas, reclamando su aprobación para el Consejo real. que sólo habia enteridido en estos casos cuando se habia litigado ante el mismo en aplicación de alguna ordenanza. Sin embargo, en el ámbito señorial no fueron pocas las localidades que elevaron para su aprobación al señor las ordenanzas que ellos mismos habian redactado; esto si no era el propio señor el autor de las mismas.

Resulta particularmente notable el hecho de que, en ocasiones, en los originales de las ordenanzas nos encontremos, dentro del articulado de éstas, las que fueron aprobadas y las que fueron rechazadas. Éstas últimas aparecen tachadas o con una anotación al margen. como en el caso de las ordenanzas de abastos y policia rural de Méntrida de 1567, cuando fueron sometidas a la aprobación del duque del Infantado, quien habia encargado al concejo su redacción ". Con tales anotaciones podemos estudiar el juego de intereses existentes entre los distintos sectores del concejo y las pugnas, muchas veces sordas, entre señores y vasallos.

Un plan amplio para el estudio del mayor número posible de ordenanzas, como el que nos planteamos acometer en los próximos años, exigiría la edición de parte de las innumerables que aún permanecen sin publicar y el comentario estandarizado de las mismas, según el modelo que en los ejemplos aplicamos, para, en una segunda fase, proceder al estudio conjunto de las mismas, desde el punto de vista del derecho sancionador y procedimiento administrativo contenido en ellas.

La estructura de las ordenanzas suele ser básicamente la misma: una disposición bien prohibitiva, bien impositiva de una conducta determinada. cuya contravención viene castigada con una multa generalmente pecuniaria, sin que falten las corporales, de cárcel y las penas accesorias. El procedimiento inquisitivo suele ser sumario, expeditivo y oral, utilizándose en la determinación de la infracción varias vías: la de cercania, la de pesquisa y el procedimiento in fraganti. La multa, por su parte, puede tener tanto un caracter retributivo (imposición de multa), como indemnizatorio, pudiendo elegir el afectado entre el pago del daño o el aprecio del mismo.

Para llegar a esa exposición conviene estudiar las ordenanzas desglosándolas por bloques temáticos, más que por su distribución geográfica, siendo un esquema útil el siguiente: 
- Abastos

- Aguas.

- Bienes Comunales.

- Concejos (ordenanzas generales o de organización administrativa).

- Gremios.

- Mesta.

- Montes.

- Oficios.

- Pastos y ganaderia.

- Pósito.

- Bienes de Propios.

- Rentas.

- Terminos.

En realidad. esta división podriamos reducirla a los siguientes apartados:

- Policia rural.

- Policía urbana.

- Política de abastos.

- Rentas, propios y comunes.

- Organización administrativa del municipio.

Evidentemente, al tratarse de docurnentos histórico-juridicos, las ordenanzas municipales pueden estudiarse desde dos puntos de vista: desde el punto de vista de medievalistas y modernistas interesa el estudio de los datos institucionales, económicos o sociales que suministran indirectamente las ordenanzas ". Desde la perspectiva de la historia del Derecho interesan tanto por su estructura externa - to que ha hecho Esteban Corral en orden a la elaboración, aprobación, contenido material, publicación, vigencia; etc.-- como por su contenido institucional, y, más concretamente, por lo que se refiere al procedimiento administrativo, en su doble vertiente inquisitiva y sancionadora.

A continuación vamos a exponer un ejemplo de policía gremial; se trata de una impugnación de ordenanzas aprobadas por el concejo contra las prácticas ilicitas de zapateros y curtidores. Éstas proceden de los momentos iniciales del siglo XVI, si bien se alega un documento de Fernando IV.

En este sentido. son modélicas las introducciones a sus respectivos textos de $\mathrm{E}$. de la $\mathrm{C}$. Aguilar en las mencionadas ordenanzas de Segura, y de D. Bohorquez (Ordenanzas del concejo de Valencia de Alcantara. Caceres 1982). sin embargo. en otros muchos casos se editan $\sin$ nin. guna introduccion o con una relacion de hechos historicos relativos a la villa o ciudad en cuestion

En cuaiquier caso seria de desear que se numerase escrupulosamente el articulado de estos textos, a fin de poder citar convenientemente los distintos capitulos. 


\section{Las Ordenanzas de curtidores y zapateros de Úbeda}

El día 15 de marzo de 1508 comparecieron ante la justicia ubetense Jorge de Ventaja y Alonso Fernández de la Puebla, procuradores de la cofradia de San Pedro y San Pablo, y presentaron un requerimiento contra las ordenanzas recientemente aprobadas por el Concejo, pues resultaban agraviados en varios de los puntos en ellas conteridos.

Muy nobles señores Justiçia e regimiento desta Noble e Muy Leal Çibdad de Ubeda. Jorge de Ventaja e Alonso Ferrnandes de la Puebla a Antón de Caçorla e Françisco de Santestevan. por nosotros y en ronbre del Cabildo de los menestrales de la çapatería desta dicha Çibdad de Ubeda que agora son cofradres de San Pedro e San Pablo, e Alonso de Pedrosa e Françisco de Madrid e Alonso de Quesada e Pero Lopez çapateros. por nosotros y en nonbre de los otros çapateros de la dicha Çibdad. pareçemos ante vuestra merçed e dezimos que a nuestra notiçia es venido que por su mandado se mandaron pregonar çiertas hordenanças çerca de la coranbre que en la dicha tenería los dichos cofadres e menestrales de la dicha çapateria hazen e venden e curten, entre las quales dichas orde. nanças algunas dellas son perjudiçiales al bien público desta dicha Çibdad e contra las premáticas destos Reygnos e espeçialmente contra los previllejos que los dichos menestrales e cofradres tenemos de la Reyna. nuestra sehora. e de los Reyes antepasados de gloriosa memoria. usados e guardados de tanto tienpo acá que memoria de onbres no es en contrario. los quales agravios son los syguientes:

[1] Lo uno. somos agraviados en mandar como, senores, mandan que nuestras mercadurias e coranbre e cumaque no las podamos vender a forastero ni los forasteros las puedan conprar de nosotros, la qual es contra las dichas prematicas destos Reynos, por ser como es manera de estanco e vedamiento general, que es proybido, e asy mismo es contra el dicho previllejo por el qual sus altezas nos dan libertad para que libremente podamos llevar nuestras mercadurias por estos Reygnos de un lugar a otro

2j Yten. somos agraviados en otra hordenança en que. senores, mandan poner veedores nuevamente. porque de tienpo ynmemorial a esta parte en la dicha nuestra casa tenemos nuestros veedores, presonas ábi les e suficientes e del mismo ofiçio. e ponerse otros estranos o de nuevo es contra nuestros buenos usos e costunbres e contra el dicho previllejo por el qual nos confirman nuestros buenos usos e costunbres. y estan confirmados espeçialmente por sentençias pasadas en cosa juzgada: e caso que veedores oviese avia de ser para que viesen la obra despues de fecha o coranbres tanto que no se herreteen, seguind que en otras partes destos Reygnos se suele fazer. e que los dichos veedores fuesen quando quisyesen syn que nosotros fuesemos obligados a los llamar

[3] Yten. reçebimos agravio en otro capitulo de las dichas ordenanças que mandan que antes que se curtan las coranbres las vean los veedores porque aquello seria ynposible hazerse syn mucho perjuyzio nuestro e del bien publico desta Cibdad. porque hera manera de dar ocasyon que se co. metiesen muchas falsedades, encubriendo unos cueros e mustrando otros 
de manera que lo más propio e conviniente para la Republica [es] que después de fecha la obra se vea y estonçes se haga lo que sea justiçia; y por esto parece asy mismo que no es necesario el heiretear ni ver antes que se curta la dicha coranbre ni después. porque seria dar ocasyon que oviese registro de nuestras haziendas. Io qual Rey no nos pone por sus leyes de quaderno.

[4] Yten, somos agraviados e asy mismo la Cibdad reçıbe perjuyzio en otra ordenança que mandan que çiertos meses no se echen suelas de corteza. porque en la verdad para el tienpo de los restrojos es muy más provechosa la suela de corteza que no de cumaque. porque en esta tierra no se curte de arrayhán. lo qual sería mejor. y en defecto dellas mejor. y asy. senores. Io hallarán la suela de corteza para el canpo, que no la de cumaque porque la de çumaque es blanda y no es buena. saivo para la Çibdad

[5] Yten. demás de lo susodicho somos agraviados en ia hordenança que dize que en syete meses del año no se echen suelas de çumaque. salvo de corteza, porque en aquel tienpo los medios puntafilos e çapatos de rostro e lengüeta e çapatos de pieça çervunos no se pueden fazer. conforme a la dicha hordenança. porque en todo tienpo conviene que se hagan con suelas de çumaque y de otra manera no se pueden fazer syn mucho perjuyzio de la obra.

[6] Yten. somos agraviados en otra ordenanca que dize que no se gasten los espaldares syno en chiquerreria, porque syendo los espaldares buenos se pueden echar en capatos nuevos de onbres. y que la obra sea perfecta e los que no son tales en la obra mediana. y las yjadas de los unos y de los otros para chapines e chequerreria, y asy se acostunbra hazer en esta Çibdad y en todas las comarcas y es perfecta la obra y desta Çibdad mas que de otras partes.

Porque pedimos e requerimos a vuestras merçedes manden ver los dichos agravios de suso nonbrados e los manden remediar mandandonos guardar nuestros previllejo e buenos usos e costumbres. e mandando asi mismo guardar las premáticas reales destos Reygnos. e si asy. senores. 10 hizieren harán to que son obligados: de otra manera protestamos de nos quexar ante quien con derecho devamos. e de cobrar de vuestras mercedes e de sus bienes las penas del dicho previllejo e costas a dapnos con el doblo. como el dicho previliejo reza. del qual hazemos presentaçion. E de como lo pedimos e requerimos al presente escrivano pedimos testimonio con lo que vuestras mercedes cerca dello mandaren proveer para guarda de nuestro derecho

Efectivamente, junto a este requerimiento presentaron el privilegio cuya aplicación invocaban: se trataba de una carta de Fernando IV, por la que colocaba bajo su encomienda al cabildo de menestrales de zapatería de úbeda, permitiéndoles moverse libremente por todo el Reino y prohibiendo 
se les prendase, salvo en las deudas y fianzas juzgadas debidamente: asimismo, reconocia la propiedad de dicho cabildo sobre unas tenerias sitas en la collación de San Juan Apóstol ":

Aunque, aparentemente, la razón asistía a los zapateros, el Concejo debió fallar contra ellos, ya que el pleito llegó ante la Chancillería de Granada el 28 de marzo de 1510, sin que sepamos el desenlace final de este contencioso por falta de documentación; sin embargo. por fortuna, conservamos el texto de las ordenanzas impugnadas por los zapateros.

Se trata de un conjunto de catorce ordenanzas, que recogemos en el Documento 2. Suponemos que debieron de redactarse a fines de 1507 o comienzos de 1508, por la fecha de impugnación de las mismas. En el preámbulo de estas ordenanzas exponia el Concejo las motivaciones de tales innovaciones, que fundamentaba en las prácticas de curtidores y zapateros de sacar fuera del término ubetense la corambre local y de curtirla de manera fraudulenta, en perjuicio de los consumidores.

A grandes rasgos, el contenido de estas ordenanzas iría encaminado a la prohibición de una serie de conductas e, inversamente. a la imposición de otras de obligado cumplimiento.

\section{Conductas prohibidas}

\section{Conducta}

Multa

-- Dar cuchilladas en los cueros $(\S 1)$

$10 \mathrm{mrs} . /$ cordobán. si traspasaren el cuero

$20 \mathrm{mrs} /$. cordobàn, si no, pena dobla. da cada vez

- Curtir cueros con lentisco $(\S 4)$

$300 \mathrm{mrs} / \mathrm{cuero}$

- Curtir cueros de ganado caballar o asnal $(\S 6)$

- Sacar cueros sin ser herrados por veedores $(\$ 7)$

- Comprar y labrar cueros sin herrar $(\S 7)$

- Comprar o vender cuero para suelas sin ser visto por los veedores $(\S 8)$

- Usar hijadas o espaldares en calzado 300 mrs. masculino $(\$ 9)$ $3.000 \mathrm{mrs}$. o pena corporal al arbitrio del juez

Pérdida del valor de lo vendido

Quema de la obra y 300 mrs, por cada vez

$300 \mathrm{mrs} . / \mathrm{cuero}$

Documento 1. Este privilegio fue confirmado sucesivamente por Altonso XI (Sevilla. 17 de junio de 1337). Enrique 11 (lliescas 5 de noviembre de 1378). Juan I (Cortes de Burgos. 14 de agosto de 1379). Enrique III (Cortes de Madrid 15 d diciembre de 1393). Juan II (Alcalá de Henares. 2 de julio de 1408) y Reyes Catolicos (Cordoba. 11 de julio de 1486). El traslado de estos documentos fue sacado en úbeda. a 24 de octubre de 1508. 
- Sacar corambre fuera del termino $(\S 11)$

- Comprar corambre el forastero $(\S 11)$
Perdida del valor de lo sacado

Pérdida de corambre y de las bestias en que la llevare

Conductas impuestas

\section{Conducta}

- Notificar las cuchilladas los compradodores del cuero ( $\$ 1$ )

- Curtir adecuadamente la corambre. según procedimiento descrito $(\S 2)$

-.. Asentar debidamente los cueros. segun procedimiento descrito $(\S 3)$

- Colocar debidamente los cueros (\$5)

- Dejar hijadas e espaldares para chapines y chiquerreria $(\S 8)$

- Echar en verano suelas de zumaque o arrayán $(\S 10)$

- Echar en invierno suelas de corteza. tenado o arrayán ( $\$ 10$ )

- Echar en cualquier época estas suelas en el calzado femenino $(\$ 10)$

- Herrar la corambre curtida por los veedores $(\$ 11)$

- Registrar la corambre importada ante el escribano de concejo (\$ 11)

- Pregonar la corambre a exportar tres dias ante escribano en las calles Real $y$ de Armas ( $\$ 11$ )

- Registrar los forasteros la corambre im. portada ante escribano de concejo, y notificar la saca ( $\$ 12)$

- Cumplir su cometido los veedores (§ 13)

\section{Multa}

Pena identica a los desoltadores

$60 \mathrm{mrs} . /$ cuero

$300 \mathrm{mrs} . / \mathrm{cuero}$

$10 \mathrm{mrs} / \mathrm{badana}$

20 mrs./ cordobán

$60 \mathrm{mrs}$ / cuero cervuno

$300 \mathrm{mrs} . / \mathrm{cuero}$

$300 \mathrm{mrs}$

$300 \mathrm{mrs}$

$300 \mathrm{mrs}$

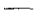

Pérdida de la corambre

Perdida de la corambre

Pena de perjuros

Poco más se recoge en estas ordenanzas; tan sólo una referencia a la elección de veedores $(\S 7)$ y la concreta designación de los mismos $(\S 13)$. A pesar de las estrictas medidas de protección de la zapateria local, el concejo establece tambien limitaciones, autorizándose la exportación de productos elaborados, con tal de que el mercado local quedase abastecido ( $\$ 11)$. Respecto al procedimiento inquisitivo, se recogen tanto la via de pesquisa como el procedimiento in fraganti (\$ 11).

Otro tema expresamente recogido en el articulo final, el 14, es el reparto del producto de las multas; éstas debian repartırse por cuartos, siendo sus perceptores la justicia, los fieles regidores, el acusador y los veedores del oficio. 


\section{DOCUMENTO 1}

\section{0, abril 2. Sevilla}

Fernando IV recibe bajo su encomienda a los miembros del gremio de zapateros de Ubeda y ieconoce la propiedad de los mismos sobre unas tenerias de la villa

Archivo de la Real Chancilleria de Granada. 506/1.073/9, fol. 7r-7v Traslado de 1508

Sepan quantos esta carta vieren como nos don Fernando, por la graçia de Dios. Rey de Castilla. de Toledo. de Leon. de Galizia. de Sevilla. de Córdova. de Murcia. de Jahen. del Algarve de Algeçira e senor de Molina. por fazer bien e merçed al Cabildo de los menestrales de la çapateria de Ubeda:

[1] Reçibolos en mi guarda e en mi encomienda e en mi defendimiento a ellos e a sus mugeres e a sus fijos e a sus ganados e a todas las sus cosas. que anden salvos e seguros por todas las partes de mis Reygnos con sus mercadurias e con todas las sus cosas que llevaren de un lugar a otro por todas las partes de los mis Reygnos. pagando sus derechos alli o los que ovieren a dar. no sacando cosas vedadas fuera de mis Reygnos. e mando e defiendo firmemente que ninguno no sea osado de les fazer tuerto ni otro mal ninguno ni de les piendar ni de les tomar ninguna cosa de lo suyo a ellos ni a sus omes que las sus cosas truxieren e llevaren de un lugar a otro por el mi senorio. como dicho es, con esta mi carta o con el traslado della signado de escrivano publico por prendas ni por demandas que se fagan de unos conçejos a otros ni de unos omes a otros ni de un lugar a otro. ni por otra razon alguna. salvo por debda conoçida o por fiaduria qu ellos ayan iecho e la debda o la fiaduria que sea ante librada e juzgada por fuero e por derecho por alli.

[2] E otrosy. otorgo a los herederos del Cabildo sobredicho de las tenerias con el solar quiollos han en IJbeda. a la collaçión de San Juan Apostol. que ovieron e han por conpra por herençia que heredaron de sus padres e de sus parientes, que las ayan libres e quitas. como las agora han. para vender e enpenar e dar e canbiar e hazer de. llas e en ellas como de lo suyo. salvo que lo no puedan vender ni enpenar ni enajenar a omes de horden ni religión ni de fuera del mi Reygno, ellos mi otros algunos por razon de toma o pecho quiel concejo de Ubeda o otros alqunos acordaren de tomar por razón de ayuda o de otra cosa alguna que les yo demande de las cofradriilas para dar a mi o a otros lugares en qualquier manera que sea.

E mando que de las dichas tenerias no tomen ninguna cosa ni de las cosas que los herederos de las cofradrli]as deste dicho cabildo o qualquier o qualesquier que lo $\mathrm{hi}_{\text {- }}$ ziosen o cointra esta merçed que les yo tago o contra alguna cosa dellas les fuesen o les passen pechar y an en pena mill maravedies de la buena moneda e a ellos e a quien su boz loviese todo el dapno e el menoscabo que por ende recibiesen con el dublo. e sobresto mando a los alcaldes e juezes que agora son en Ubeda e serán de aqui adelante e a todos los conçejos. alcaldes juezes, justiçias. alguaziles maestres de las ordenes que agora e de aqui adelante [esten] por mi en la frontera que no consyentan a ninguno que les pase contra esta merçed que les yo tago en ninguna cosa. por cartas mias que tengan ni muestren que contra esta sean, e sy alguno o algunos lo fizieren que les prenden por la pena sobredicha de los mill maravedies e los 
guarden para fazer dellos lo que yo mandaré e fagan emendar luego a los herederos de las dichas tenerias e a los omes buenos del dicho cabildo o a quien su boz toviere de todo el dapno e el menoscabo que por ende reçibieren con el doblo. como dicho es. e no fagan ende al so la pena sobredicha. e sobresto mando a los escrivanos públicos de las villas e de los lugares do esto acaesçiere que para esto fueren llamados a boz del dicho cabildo e de los herederos de las tenerias sobredichas o de qualquier dellos o de los cofradres. que les den testimonio signado con su sygno porque yo sepa en cómo se cumple esto que yo mando e mande sobrello lo que toviere por bien e no fagan ende al so la pena sobredicha, e desto les mandé dar esta carta sellada con mi sello de plomo. Dada eri Sevilla, dos dias de abril, hera de mill e trezientos e quarenta e ocho años. Yo Bartolome Gonçales la fiz escrevir por mandado del Rey. Gonçalo Garçia, vista. Ruy Lopez. Juan Martínez.

DOCUMENTO 2

[1507- 1508]

El Concejo de Ubeda, con el fin de remediar los abusos que se cometian en la saca y curtido de la corambre. aprueba un conjunto de ordenanzas sobre el particular.

ARChG, ibidem, fol. 12r-14r. Traslado de 1508: existe otra copia de las mismas ordenanzas en letra distinta dentro de la misma pieza.

Nos el Conçejo. justiçia, regimiento de la Noble e Muy Leal Çibdad de Ubeda, hazemos saber a los juezes e alguaziles e veedores desta dicha Cibdad que agora son o serán de aqui adelante que a nuestra notiçia es venido que muchas presonas de los vezinos e moradores de la dicha Cibdad y de otras partes. con poco themor de Dios e de la justiçia. sacan desta Çibdad y sus términos muncha coranbre, asy en pelo como cortida. de lo qual redunda mucho dapno a la utilidad pública desta Çibdad, y asy mismo somos ynformados que algunos de los cortidores e çapateros que curten en las tenerias desta Cibdad curten los cueros. asy vacunos e cabrios como la otra coranbre. muy falsamente. y sacan los dichos cueros del cortido e los venden e labran en borzeguies e çapatos e otros calçados, syendo quemados e crudos y falsamente cortidos. de lo qual la República e vezinos e moradores desta Çibdad y las otras presonas que conpran la dicha coranbre y calçado reçiben mucho dapno.

Por ende. queriendo proveer el remedio de lo susodicho. acordamos con deliberaçion de ordenar y estableçer las ordenanças que adelante dirán. en esta guisa:

[1] Primeramente. que los carniceros y rastreros y las otras presonas que desuellan las reses, asy en las carneçerias y rastros desta Cibuad como fuera delios. desuellen ellos y sus criados las reses bien desolladas, por manera que los cueros no lieven guchilladas. so pena por cada guchillada que pasare ol cuero de cordovan de diez maravedies. y la que no pasare yncurra en pena de veynte mrs: y en los cueros de las 
vacas pague la pena doblada: y que las presonas que conpraren la dicha coranbre. luego que la conpraren notifiquen a los veedores las guchillada o guchiladas que la tal coranbre llevare. so la dicha pena.

[2] Otrosy. ordenamos e mandamos que todos los cortidores desta Cibdad e los que tovieren cabdales en las tenerias della y entendieren en el trato del cortir de la coranbre la curtan y tagan cortir muy bien. teniendo en el dicho cortido los cueros todo el tienpo neçesario en esta guisa: Ios cueros vacunos los traygan en buenos pelanbres con cal nueva, e sean alçados los pelanbres a lo menos dos vezes en la semana. e que no anden en cal vieja. porque no tomen percox. e que sean duces e no pelanbrados. e despues desatados de los pelanbres para les dar las lavores para los cortir les den seys lavores de teja e guchilto, so pena de sesenta mrs. por cada cuero. e que no 10 gasten fasta ser fecho perfecto a vista de los veedores.

[3] Yten. en quanto al asentar de los cueros de corteza questen treynta días en la primera corteza nueva e después de los treynta dias sean sacados del noque e sacodidos de la corteza vieja. e sean asentados en los tinajones o noque con otra corteza nueva y esten otros treynta dias. e que antes no los puedan sacar para gastar fasta ser conplidos los dichos treynta dias e vistos por los veedores. so pena de trezientos mrs. por cada cuero.

14] Yten. que la dicha orden se tenga en el cortimiento de los cueros que han de ser tenados. e quéstos no heven lantisco. pero los que han de ser de çumaque. porquel cumaque desta tierra es algo flaco. premetimos que sean traydos con lantisco con la cantidad dello que a los dichos veedores pareçiere. para que la obra sea buena. y lo contrario faziendo yncurran en la susodicha pena

[5] Yien. que los cordovanes y badanas e cervunos e baldreses los traygan en pelanbres nuevos con cal nueva, e los echen duçes e no pelanbrados. porque seyendo asy fechos e con buen cumaque cortidos tomaran bien las colores: los quales no saquen de los pelanbres syn liçençia e vista de los veedores. so pena de diez mrs. por cada cuero de badana y del cordován veynte y del cervuno sesenta mrs.

[6] Yten. que no puedan cortir cueros de cavaltos ni mulos ni yeguas ni asnos: so pena de tres mill mrs.. y sy no los tovieren paguen en el cuerpo como al juez bien visto fuere

[7] Otrosy, ordenamos y mandamos que porque la dicha coranbre sea bien cortida e los vezinos e moradores desta dicha Çibdad no sean agraviados en los calçados que an de gastar. que agora e de aqui adelanie de cada un año sean elegidos por la jus. tiçic e regidores de la dicha Cibdad uno o dos onbres buenos de los vezinos de la dicna Cibdad que sean maestros e sabidores en el arte e oficio de cortir que tengan especial cargo de ver e requerir las dichas coranbres e que no se saquen del cortido ni se vendan syn que primeramente los dichos veedor e veedores las vean sy están bien cortidas e las hierren del hierro que para esto la Cibdad les diere. porque sepan los conpradores que los dichos cueros estan bien cortidos e bien adobados: e que los puedan cortar e labrar syn pena alguna. e sy algunos de los dichos cortidores sacaren los dichos cueros del dicho cortido syn ser vistos y herrados del dicho veedor o veedores e los vendieren. que ayan perdido el valor de los dichos cueros. y el que los conprare y cortare y tabrare que le quemen la obra e calçado que dellos fizieren. e demas que pague en pena trezientos mrs. por cada vez que le fuere fallado o provado.

[8] Otrosy. ordenamos e mandamos que ningund cortidor ai cabdalero no sea osado de vender ningúnd cuero para soleria ni los capateros lo conpren $n \neq$ lo corten 
syn que sean vistos por los dichos veedores: y que dexen las yjadas y espaldar para los otros calcados de chapines y chiquerreria que los otros semejantes calcados. so pena que sy lo vendieren o recaçaren syn ser visto y senalado de los dichos veedores. que paguen trezientos mrs. por cada cuero.

[9] Otrosy. que las dichas yjadas y espaldar no gasten los çapateros en calçado de onbres. so la dicha pena

[10] Otrosy. por quanto somos ynformados que las suelas de corteza que se echan en los çapatos de correa o de obra prima no es buena ni provechosa en el verano. conviene a saber. desde el primero dia de mayo fasta en fin dei mes de setienbre. por ende. ordenamos e mand[amjos que agora e de aqui adelante los capateros de obra prima e de correa los dichos meses echen suelas en los çapatos que hizieren cortidas de cumaque e no de otro cortido alguno. sy no fuera de arrayhan. e los otros meses de ynvierno. que son otubre e novienbre e dizienbre e encro y hebrero y março e abril echen los capatos suelas cortidas de corteza o tenado. e no de otro cortido alguno. sy no fuere del dicho arrayhán. porque para tudo tienjo es bueno. Pero que en el calcado de las mugeres e soletas de borzequies puedan echar suelas de cumaque o de te. nado en todo el ano. e el que lo contrario fiziere pague de pena trezientos mrs. por cada vez que lo fiziere o le fuere provado

[11] Otrosy. por quanto somos ynformados que muchos de los cortidores y capateros desta dicha Cibdad venden la mejor coranbre que en ella se curte para fuera parte. de que los vezinos e moradores desta Cibdad reciben mucho dapno. Por ende hordenamos e mandamos que agora e de aqul adelante los dichos cortidores e capateros ni otra presona alguna no sean osados de vender ni sacar para fuera parte ninguna coranbre. asy en pelo como cortida. de la que en esta Cibdad e en su tierra se matare. so pena que la presona que vendiere para fuera parte la dicha coranbre yncurra en pena del valor de lo que asy vendiere. v ol que la conprate plerda la dicha coranbre y las besthas en que la sacare. syendo tomado con la dicha coranbre. o sy fuere sabido e provado que la vendio e sacó contra el thenor e torma desta dicha ordenança.

Pero premetimos que los capateros y borzeguneros e otros oficiales e otras presonas qualesquier. asy vezinos como torasteros. puedan libre e desenbargadamente sacar la dicha coranbre labrada en capatos e borzeguies e syllas e nendas e abcio nes e chapines e en los otros calçados. con tanto que la dicha Çibdad este syenpre proveyda y abastada de las dichas cosas: Io qual se pueda sacar tanto cuanto la voluntad de la Cibdad fuere e vean que no es en perjuyzio del bien público desta dicha Cibctad.

Pero por quitar achaques premetimos e mandamos que los que overen de cortir coranbre de ta que en esta Cibdad e su tierra oviere. que despues de cortida la notifquen a los veedores porque la fierren e den cuenta o razon della pero porque no cese el trato de la dicha coranbre. que la coranbre que truxieren los vezinos desta cibdad de fuera parte la registren antel escrvano de Concejo. como se [a]costunbro. y sy la quisieren llevar fuera parte o vender a forasteros. faganla tres dias pregonar por antel dicho escrivano por las Calles de las Armas y Real. para que sy la quisieren conprar los oficiales y pasados los térmınos de los pregones la puedan sacar o vender a fuera parte. dando el dicho escrivano alvala conforme al registro. y lo contrario faziendo yncurran en la dicha pena de la aver perdido.

[12] Yten que las presonas que truxieren coranbre de fuera parte. que no son vezinos. para la cortir en esta Cibdad. la registren ante escrivano de Cabildo y no la sa- 
quen syn lo noteficar a la Cibdad. porque sy toviere neçesidad de gastar en ella se gaste. y sy no le dé liçençia para la sacar.

[13] Y porque lo susodicho sea guardado, nonbramos por fieles e veedores del dicho ofiçio para en un año conplido y más quanto fuere nuestra voluntad a Françisco Sahagún e a Pedro Delgado. vezinos desta Çibdad, por ser presonas ábiles e sufiçientes. Ios quales ante nos juraron de usar bien e fielmente del dicho ofiçio e de notificar a la justiçia todo el dapno e falsedad que vieren que en el dicho cortimiento e lo a él tocante oviere, so pena de perjuros y de las otras penas en derecho estableçidas.

[14] $Y$ que aviendo esecuçión en todo to susodicho, mandamos que las susodichas penas se repartan e las ayan la quarta parte la justiçia y la otra quarta parte los nuestros fieles regidores e la otra quarta parte el acusador e la otra quarta parte los dichos veedores del dicho ofiçio. 